\title{
COMPROMETIMENTO
}

\section{ORGANIZACIONAL E PRÁTICAS DE GESTÃO DE RECURSOS HUMANOS: O CASO DA EMPRESA XSA}

\section{ORGANIZATIONAL COMMITMENT AND HUMAN RESOURCE PRACTICES: THE "XSA" CASE}

VERA L. CANÇADO

Professora no Mestrado Profissional das Faculdades Integradas de Pedro Leopoldo.

Doutora em Administração e Mestre em Organizações e Recursos Humanos pelo Centro de Pós-Graduação e Pesquisas em Administração da Universidade Federal de Minas Gerais (CEPEAD/UFMG). Psicóloga pela PUC - MG. Rua Fernando Esquerdo, 35, ap. 303, Gutierrez - Belo Horizonte - MG - CEP 30430-000

E-mail:vcancado@uai.com.br

LÚCIO FLÁVIO RENAULT DE MORAES Professor no Mestrado Profissional das Faculdades Integradas de Pedro Leopoldo. Pós-doutorado em Comportamento Organizacional pela Australian Catholic Universith, Austrália Pos-doc., e pela Aston Universith/Universith of Manchester, Reino Unido. Doutor em Liderança e Comportamento Humano pela United States International University, Estados Unidos. Rua Mato Grosso, 666, ap. 1.201, bl. B, Barro Preto - Belo Horizonte - MG - CEP 30190-080 E-mail: luciorenaulł@gmail.com

EDSON MOURA DA SILVA Mestre em Administração pela Fundação Pedro Leopoldo. Pós-Graduação em Administração de Recursos Humanos pela Fundação João Pinheiro. Psicólogo pelo Instituto Cultural Newton Paiva Ferreira. Av. Hum, 336, ap. 101, Novo Santa Cecília - Belo Horizonte - MG - CEP 30626-660 


\section{RESUMO}

A relação indivíduo/organização tem sido fonte de vários estudos por parte da Administração, que buscam promover e incentivar o envolvimento do indivíduo com as empresas, reduzir conflitos e aumentar a produtividade. Uma das vertentes desses estudos foca o comprometimento organizacional como uma das maneiras de se compreender como se instauram os vínculos entre o indivíduo e a organização. O comprometimento deve ser entendido também como um recurso empresarial para amenizar perdas e prejuízos. Neste trabalho, busca-se verificar quais são as práticas utilizadas pela gestão de recursos humanos nas empresas, incluída a gestão do conhecimento, para obter o comprometimento dos seus funcionários, utilizando-se o modelo de Meyer e Allen, focado nos três componentes: afetivo, normativo e instrumental. Para tal, foi realizada uma pesquisa em uma empresa de operação logística de Minas Gerais, aqui denominada de XSA, com a aplicação de questionário a uma amostra selecionada de 93 funcionários. Constatou-se que as práticas de recursos humanos investigadas influenciam as dimensões afetiva e normativa do comprometimento. Os índices mais elevados, que explicam essas dimensões de comprometimento, foram observados nas práticas de gestão do conhecimento e nas práticas de relacionamento, revelando que elas são componentes essenciais para manter os vínculos dos funcionários com a empresa.

\section{PALAVRAS=CHAVE}

Comprometimento organizacional; Gestão de recursos humanos; Gestão do conhecimento.

\section{ABSTRACT}

The relation individual/organization has been source of several studies on management. Those studies seek to promote and to stimulate the individuals' involvement to the company, reducing conflicts and increasing the productivity. One approach of such studies focuses on the organizational commitment as one of the ways of understanding the ties between the individual and the organiza- 
tion. This paper aims to present the relation between the human resources practices used by the companies, including the knowledge management, and the employees' commitment. To analyze the commitment we used the model of Meyer e Allen, focusing on three components: affective, normative and instrumental. The empirical research was undertaken in a logistic company of the State of Minas Gerais, from now on designated as XSA. The data was obtained from a questionnaire applied to a selected and representative sample of 93 employees. The results showed that human resources practices have influenced the affective and normative dimensions of the commitment. The higher rates were observed in the practices of knowledge and relationship management. So, we can conclude that those practices are essential to keep the employees ties with the company.

\section{KEVWORDS}

Organizational commitment; Human resources management; Knowledge management.

\section{INTRODUÇÃO}

A área de Administração de Recursos Humanos (ARH) tem buscado diversas fórmulas e mecanismos que permitam promover o envolvimento do indivíduo em suas atividades cotidianas, com o mínimo de conflitos e o máximo de desempenho. Apesar de sua relevância no âmbito organizacional ser um consenso aparente, RH ainda não conseguiu demarcar um espaço concreto e legítimo de atuação. Entretanto, no decorrer dos últimos anos,

[...] frente às mudanças que cercaram a realidade empresarial, tal perspectiva teve que ser ampliada, no mínimo, com uma preocupação efetiva com o elemento humano, entendido como ponto-chave do processo produtivo (SARSUR, I999).

Diversas têm sido as práticas de RH nesse sentido, desde o cumprimento de sua função burocrática de promover o registro e a movimentação de pessoal até a tentativa de atuação no nível estratégico, contribuindo para o negócio da empresa. Complementando essas práticas, surgem, ao final do século XX, os modelos de gestão do conhecimento como uma proposta para incentivar a criatividade, a flexibilidade, o trabalho em equipe e a criação de redes, de modo a manter as pessoas articuladas e comprometidas com o resultado, levando a um desenvolvimento sustentável nas organizações. 
Diante desse ambiente competitivo e em função da complexidade dessa relação, a análise sobre o vínculo entre o indivíduo e a organização tem-se aprofundado nessas últimas décadas, intensificando-se, entre outros, os estudos sobre comprometimento organizacional, o qual pode ser definido como o vínculo estabelecido entre o indivíduo e a organização. Várias pesquisas (MORAES; MARQUES, I996; ZEHURI, I997; MEDEIROS, I997; RANGEL, 200I, dentre outras) demonstraram que o vínculo do trabalhador com a organização é influenciado diretamente pela identificação e pelo significado da tarefa, bem como por fatores contextuais, como satisfação com o ambiente social e incentivo por meio de recompensas. Contudo, os estudos que focalizam a relação entre as práticas de recursos humanos e o comprometimento organizacional são recentes e ainda pouco numerosos. No final da década de I990, Bandeira (1999) realiza uma pesquisa em uma empresa pública de prestação de serviços, comprovando a existência de correlação entre as práticas de recursos humanos (variável independente) e o comprometimento organizacional (variável dependente). A autora partiu da premissa de que "é possível conseguir diferencial e vantagem competitiva no mercado através de uma estratégia de $\mathrm{RH}$ voltada para comprometer o empregado com os objetivos organizacionais" (BANDEIRA, I999, p. 2). Ela comprova, por meio de sua pesquisa, que a área de $\mathrm{RH}$, mediante suas práticas, busca estabelecer uma forma de relação mais adequada entre a empresa e seus funcionários, com o objetivo de influenciar o comportamento e o comprometimento do indivíduo com a organização.

Diante dessa argumentação, emerge o questionamento central deste artigo: Quais são as práticas utilizadas pela área de RH nas empresas para obter o comprometimento dos funcionários? A partir desta questão, busca-se analisar em que medida as práticas de recursos humanos contribuem para o estabelecimento e a manutenção do vínculo do funcionário com a empresa. Este trabalho avança ao incluir nas práticas de RH a gestão do conhecimento. São discutidos os dados de um estudo de caso, realizado por Silva (2003), em uma empresa de logística, de atuação em âmbito nacional, denominada de XSA, que desenvolve práticas sistematizadas de administração de RH e vem passando por um processo recente de implantação de gestão do conhecimento.

Busca-se investigar a correlação entre as práticas de recursos humanos adotadas pela empresa, incluindo as práticas de gestão do conhecimento, e os padrões de comprometimento organizacional. A pesquisa foi baseada no modelo de comprometimento organizacional de Meyer e Allen (I99I), focando os componentes afetivo, normativo e instrumental e utilizando um questionário adaptado do instrumento validado por Bandeira (1999). 


\section{REFERENCIAL TEÓRICO}

\section{1 ADMINISTRAÇÃO DE RECURSOS HUMANOS}

A área de Administração de RH tem acompanhado o desenvolvimento das organizações e de seus modelos teóricos. Para uma melhor compreensão dos modelos e práticas de administração de recursos humanos nas organizações, faz-se necessário realizar uma contextualização histórica sobre a evolução e as fases marcantes no Brasil, conforme apresentado no Quadro I.

\section{QUADRO I}

\section{EVOLUCAO DA FUNCAOO RECURSOS HUMANOS NO BRASIL}

\begin{tabular}{|c|c|c|}
\hline PERÍODO & FASE & CARACTERÍSTICAS \\
\hline $\begin{array}{l}\text { Antes de } \\
1930\end{array}$ & $\begin{array}{l}\text { Pré-jurídico- } \\
\text { trabalhista }\end{array}$ & $\begin{array}{l}\text { - Inexistência de legislação trabalhista e de Departamento de Pessoal; } \\
\text { - reflexos do período escravagista sobre o tratamento da mão-de-obra. }\end{array}$ \\
\hline $\begin{array}{l}\text { Décadas de } \\
1930 \text { a } 1950\end{array}$ & $\begin{array}{l}\text { Legal / } \\
\text { Burocrática }\end{array}$ & $\begin{array}{l}\text { - Regulamentação das relações de trabalho: legislação trabalhista - CLT; } \\
\text { - criação do Ministério do Trabalho; } \\
\text { - surgimento do Departamento de Pessoal para atender às exigências legais. }\end{array}$ \\
\hline $\begin{array}{l}\text { Décadas de } \\
1950 \text { e } 1960\end{array}$ & Tecnicista & $\begin{array}{l}\text { - Planejamento do parque industrial / implantação da indústria automobilística; } \\
\text { - abertura ao capital estrangeiro; } \\
\text { - criação da área de Relações Trabalhistas em resposta às demandas industriais; } \\
\text { - preocupação com eficiência e produtividade. }\end{array}$ \\
\hline $\begin{array}{l}\text { Meados das } \\
\text { décadas de } \\
1960 \text { a } 1980\end{array}$ & Sistêmica & $\begin{array}{l}\text { - Movimentos populistas e greves; } \\
\text { - revolução de } 64, \text { que acabou com a pseudoliderança sindical; } \\
\text { - novos investimentos das empresas gerados pelo governo do general Médici, } \\
\text { que inspira otimismo e confiança; } \\
\text { - crise do petróleo; } \\
\text { - falta de mão-de-obra especializada; } \\
\text { - surgimento da Gerência de RH e dos seus subsistemas; } \\
\text { - incorporação de enfoque comportamental; } \\
\text { - surgimento do movimento da qualidade. }\end{array}$ \\
\hline $\begin{array}{l}\text { Década de } \\
1990\end{array}$ & Estratégica & $\begin{array}{l}\text { - Consolidação do processo de internacionalização dos mercados e globaliza- } \\
\text { ção econômica; } \\
\text { - aumento da competitividade; } \\
\text { - novos desenhos organizacionais: reengenharia e reduções de níveis hierár- } \\
\text { quicos; } \\
\text { - acentuado avanço tecnológico; } \\
\text { - crise social e econômica: mudanças com relação ao conceito de emprego } \\
\text { tradicional; }\end{array}$ \\
\hline
\end{tabular}


QUADRO I (CONTINUAÇÃO)

EVOLUCAO DA FUNCÂO RECURSOS HUMANOS NO BRASIL

\begin{tabular}{|c|c|c|}
\hline PERÍODO & FASE & CARACTERÍSTICAS \\
\hline $\begin{array}{l}\text { Década de } \\
1990\end{array}$ & Estratégica & $\begin{array}{l}\text { - novas relações de trabalho; } \\
\text { - flexibilização; } \\
\text { - exigência de um novo perfil de profissionais e necessidade de uma nova } \\
\text { postura empresarial no trato com o elemento humano } \rightarrow \text { empregabilidade } \\
\text { e empresabilidade; } \\
\text { - desafio à função RH: necessidade de repensar sua posição e adotar novas } \\
\text { práticas. }\end{array}$ \\
\hline
\end{tabular}

Fonte: Adaptado de Wood Jr. (I995) e Sarsur (I997).

Diante dessas evidências, concorda-se com Fleury e Fischer (1992), que ressaltam a lentidão da evolução histórica da Administração de Recursos Humanos no Brasil e sua linha de atuação eminentemente técnica, voltada para atividades burocráticas e administrativas. Para as autoras, dois fatores marcaram significativamente a transformação dos modelos e das práticas de RH na década de I990: o fortalecimento do sindicalismo, que surgiu como personagem marcante no cenário político, inaugurando formas mais participativas e propondo diálogo com o empresariado; e a ampliação das discussões sobre as condições de trabalho, trazidas com a Constituição de I988. A abertura do mercado brasileiro na década de I990, com o rompimento das barreiras nacionais e a introdução das novas relações comerciais, constitui fator alavancador na gestão de RH, segundo Wood Jr. (I995). Em nível intra-organizacional, o modelo taylorista-fordista, que caracterizou a organização do trabalho neste último século, tende a ser substituído por sistemas de gestão mais flexíveis e adaptáveis, demandando uma atuação mais ampla de RH, principalmente em nível estratégico.

A partir dessas demandas sobre a função RH, pode-se estabelecer uma diferenciação entre a visão tradicional e a visão mais atual da área. A visão tradicional é caracterizada por focar as atividades inerentes à função técnica, como seleção e treinamento de pessoal, constituindo apoio ao desenvolvimento operacional da empresa. Não se constata uma visão de negócio, de resultados, sendo a função RH mais voltada para o nível da execução de suas especialidades. A visão atual, que desponta como uma tendência emergente, foca o fator humano como a chave principal para o sucesso organizacional, apresentando uma preocupação com o alinhamento das práticas de RH e com as diretrizes e estratégias da empresa (WOOD JR., I995; LINS; ZÚNIGA, I999). 
Diante desse cenário, a função RH precisa assumir um posicionamento estratégico nas organizações e suas atividades devem estar focadas no negócio e no desenvolvimento da organização, a partir do investimento nos funcionários e nos processos. Preconiza-se, assim, a sua atuação em diferentes papéis integrados: parceria estratégica, agente de mudança, especialista administrativo e defensora dos funcionários (ULRICH, I998). Na atualidade, uma das práticas adotadas pela ARH é a gestão do conhecimento, que, mediante o desenvolvimento dos funcionários, possibilita a disseminação interna das melhores práticas para a geração de diferencial competitivo para a organização.

\section{2 . 2 GESTÃO DO CONHECIMENTO}

A gestão do conhecimento tem sido enfatizada por diversos autores como uma fonte inesgotável de recursos para o desenvolvimento das organizações no mundo atual. Empresas inovadoras e competitivas são aquelas que desenvolvem a habilidade de gerenciar o conhecimento, incorporando-o aos seus produtos e serviços. Neste cenário, a gestão do conhecimento e a implementação de uma cultura da aprendizagem devem estar inseridas no conjunto de estratégias das empresas e das estratégias da ARH (LEONARD-BARTON, I998; DAVENPORT; PRUSAK, I998; EDVINSSON; MALONE, I998).

Para Terra (2000), a relevância do capital humano como vantagem competitiva para as organizações está relacionada ao conhecimento tácito que seus funcionários possuem, bem como às suas competências individuais, habilidades e atitudes. Dentre as várias perspectivas conceituais, a proposta de Sveiby (I998), citado por Campos e Barbosa (200I, p. 8), parece sintetizar as definições propostas por outros autores:

Gestão do conhecimento é a arte de criar valor alavancando os ativos intangíveis. Para conseguir isso, é preciso ser capaz de visualizar a empresa apenas em termos de conhecimento e fluxos de conhecimento.

A gestão do conhecimento pode ser entendida como processo, diferenciado em três momentos distintos, conforme proposto por Vasconcelos (2002):

a) geração do conhecimento;

b) transferência do conhecimento;

c) retenção do conhecimento, ou registro da memória. 
Na etapa de aquisição e geração do conhecimento, podem-se incluir tanto o conhecimento adquirido como o conhecimento desenvolvido pela organização. Segundo Leonard-Barton (I998), a geração do conhecimento está relacionada à abrasão criativa, advinda de pessoas com diferentes habilidades, idéias e valores, que podem gerar soluções criativas e inovação. Isso ocorre nas fronteiras entre as mentes, não dentro do território provinciano de uma só base de habilidades e conhecimento. Para Davenport e Prusak (I998), as empresas têm incentivado, mediante a criação de prêmios, a aquisição de conhecimento novo para a organização. Se o conhecimento só pode ser gerado por indivíduos, a organização precisa apoiar os indivíduos criativos e proporcionar-lhes contextos para a criação do conhecimento.

Em relação à segunda etapa, a transferência do conhecimento nas organizações pode processar-se de maneira formal ou informal. As empresas devem incentivar os encontros informais, dentro e fora do ambiente de trabalho, para estimular os colaboradores a discutirem problemas organizacionais, a articularem estratégias, a solucionarem dúvidas e, principalmente, a trocarem experiências. Segundo Davenport e Prusak (I998), as reuniões face a face são os maiores e melhores canais de transferência de tecnologia e conhecimento que existem: as salas de bate-papo estimulam a criatividade das pessoas por possibilitarem transferências cotidianas do conhecimento que fazem parte da vida organizacional. A transferência da aprendizagem individual para a aprendizagem organizacional efetiva-se no processo pelo qual a aprendizagem individual torna-se inserida na memória e na estrutura da organização.

Na etapa de codificação do conhecimento, ou de construção da memória, objetiva-se apresentar este conhecimento de tal maneira a torná-lo acessível àqueles que dele necessitem. Para efetivar a codificação, as organizações utilizam as tecnologias da informação e os processos de comunicação que sejam capazes de gerar maior agilidade na inovação e na mudança tecnológica. Segundo Vasconcelos (2002), há uma dificuldade em se codificar e registrar o conhecimento tácito, uma vez que é quase impossível reproduzir em um banco de dados ou em documentos certos detalhes, como nadar ou andar de bicicleta. Fleury e Fleury (2000) referem-se à construção da memória organizacional como o processo de armazenagem de informações com base na história organizacional, devendo-se incluir todas as experiências, tanto as bem-sucedidas quanto as malsucedidas, para se criar conhecimento e auxiliar na tomada de decisões.

Pode-se concluir que por meio da gestão do conhecimento é possível potencializar a atuação das pessoas. Contudo, não basta somente possibilitar o aprimoramento contínuo dos funcionários. A ARH tem outro papel de igual importância, que é o de estabelecer práticas que assegurem a permanência e o vínculo do funcionário na organização. Para tal, o estudo sobre o tema comprometimento é primordial e atende aos objetivos propostos nesta pesquisa. 


\section{2 . 3 COMPROMETIMENTO ORGANIZACIONAL}

O tema comprometimento organizacional passou a ser divulgado em nível mundial a partir do clássico trabalho da equipe dos professores Mowday, Steers e Porter, na década de I970. No Brasil, o tema vem ganhando adeptos desde a década de I990, com a publicação dos trabalhos pioneiros de Borges-Andrade (I989) e de Bastos (I994), assim como daqueles elaborados pelo Núcleo de Estudos Avançados em Comportamento Organizacional (NEACO), do CEPEAD/ UFMG, coordenado por Moraes. As diversas pesquisas brasileiras - Dias (2005), Albuquerque et al. (2005), Genelhu (2004), Rego e Souto (2004), Rangel (200I), Ferreira (200I), Tamayo (2000), Medeiros (I997), Moraes (I997) e Gama (I993), dentre outras - procuraram, principalmente, formular modelos e quantificar o comprometimento e as variáveis antecessoras e correlatas.

Em uma revisão de diversos trabalhos sobre comprometimento, Mowday, Porter e Steers (I982) levantam enfoques diferenciados das diversas pesquisas realizadas, demonstrando a dificuldade de definir o tema. Conclui-se que não existe um consenso desse construto, "o que leva à aceitação de conceituações e mensurações diferenciadas”, conforme afirma Moraes (I997, p. 50). Isso implica, portanto, a necessidade de o pesquisador apresentar uma conceituação clara e o seu entendimento sobre o que pretende pesquisar.

Neste trabalho, são descritos e analisados os enfoques mais utilizados por diversos pesquisadores no Brasil nos últimos anos, ou seja, o afetivo, o normativo e o instrumental, e a conceituação de Meyer e Allen, perspectiva teórica que dá sustentação à pesquisa empírica realizada na empresa XSA.

O construto enfoque afetivo, baseado na proposta de Mowday, Porter e Steers (I982), destaca a natureza afetiva da relação de identidade do indivíduo com as metas da organização. Dentre as diversas abordagens apontadas pela literatura, Moraes (I997) ressalta que esta aparece na maioria dos estudos realizados no país. O comprometimento organizacional no enfoque afetivo pode ser conceituado como: uma forte crença nos valores e objetivos da organização e a aceitação deles; um desejo de exercer esforço considerável em favor da organização; e um forte desejo de manter-se como membro da organização. Moraes (I997, p. 53) ainda complementa dizendo que

o comprometimento afetivo representa algo além da simples lealdade passiva a uma organização. Ele envolve uma relação ativa, na qual o indivíduo deseja dar algo de si próprio para contribuir com o bem-estar da organização. 
Neste enfoque, ocorre a identificação do indivíduo com as metas organizacionais, bem como a introjeção dos valores institucionais, assumidos como se fossem próprios do indivíduo. Parte-se da suposição de que o empregado deseja dar algo de si para a organização e esforçar-se por ela. Bandeira (I999) afirma que este enfoque representa um vínculo mais forte com a organização. A identificação do indivíduo com os valores e com os objetivos da organização pode tornar-se um facilitador na consecução desses objetivos, em função da relação ativa entre o indivíduo e a organização e do desejo de manter-se como membro desta, conforme afirma Ferreira (200I).

O enfoque normativo nasce da interseção entre a teoria organizacional e a Psicologia Social, centrando-se na estrutura das atitudes e do seu poder preditivo em relação ao comportamento. Para Bastos (I994, p. 83), "esta vertente teórica procura ligar dois planos de análise: o organizacional, através do conceito de cultura, e o individual, através da motivação e do comportamento". Segundo o autor, a cultura organizacional pode produzir membros comprometidos, exercendo uma influência estável e de longo prazo. As pressões normativas predispõem o indivíduo a comportar-se segundo padrões internalizados. Contudo, dependendo do tipo de valores, essas pressões podem ser ou não construtivas para a organização. As pressões internalizadas se manifestam em comportamentos característicos de sacrifício, de persistência e de preocupação pessoal, enquanto os valores e normas compartilhados que geram o comprometimento são associados às crenças instrumentais, às conseqüências de um determinado desempenho. Para Bastos (I994):

quanto mais forte o comprometimento, maior a predisposição do indivíduo para guiar as suas ações por padrões internalizados, mais do que considerações racionais acerca das conseqüências dessas ações.

O comprometimento no enfoque normativo pode ser entendido como o vínculo do trabalhador com os objetivos e interesses da organização, estabelecido e perpetuado por meio dos valores e normas compartilhados e pelas pressões normativas internalizadas.

O comprometimento sob o enfoque instrumental constitui o segundo grande referencial teórico adotado nas pesquisas sobre o tema. Possui outras denominações, como enfoque calculativo, continuação e side-bets (do inglês, trocas laterais). Conforme afirma Bastos (I994, p. 63-64), este enfoque procura explicar 
o fato de que os indivíduos se engajam em linhas consistentes de ação ou em um comportamento consistente [...] que persiste ao longo do tempo, podendo ser definido como: um mecanismo psicossocial cujos elementos são trocas efetuadas pelo indivíduo, side-bets, nem sempre deliberadamente, mas cujas conseqüências, estranhas à ação em que estava engajado, limitam as suas decisões posteriores, mantendo-o num mesmo curso da ação.

Esse enfoque assume que o empregado decide por permanecer na empresa enquanto vislumbrar benefícios nessa escolha. Se acaso os investimentos realizados por ele forem maiores do que o retorno obtido, sua escolha certamente será pelo abandono da organização.

A conceituação do comprometimento sob o enfoque das três dimensões surgiu em decorrência dos estudos de Meyer e Allen (I990). O conceito das três dimensões resultou do trabalho de McGee e Ford (1987), que realizaram um exame das propriedades psicométricas das escalas desenvolvidas por Meyer e Allen (I984), a partir da técnica de análise fatorial, usando dois fatores. O primeiro, formado por oito itens da escala do comprometimento afetivo, demonstrou cargas fatoriais aceitáveis. O segundo, composto por oito itens da escala do comprometimento instrumental, demonstrou seis cargas aceitáveis. Assim, surgiu uma nova dimensão do comprometimento, denominada normativa, cujos itens refletiam desvantagem para o empregado na hipótese de deixar a organização (MEDEIROS, I997).

Meyer e Allen (I990) incorporaram a nova dimensão e conceituaram as três anteriores na definição do comprometimento organizacional: afetivo, instrumental e normativo, caracterizando-as da seguinte forma:

Empregados com um forte comprometimento afetivo permanecem na organização porque eles querem, aqueles com comprometimento instrumental permanecem porque eles precisam e aqueles com comprometimento normativo permanecem porque eles sentem que são obrigados.

O modelo das três dimensões de Meyer e Allen, em virtude de sua amplitude, representa uma das formas mais pertinentes de investigar o comprometimento no complexo ambiente em que se inserem hoje as organizações. Para o desenvolvimento desta pesquisa na empresa XSA, partiu-se do trabalho de Bandeira (I999), no qual foi estabelecida uma correlação entre as práticas de RH e o comprometimento organizacional. 


\section{A pesquisa REALIzAdA NA XSA}

Esta pesquisa pode ser entendida como um estudo descritivo, pois descreve as características de determinada população, ou fenômeno, e também busca estabelecer correlações entre as variáveis dependente (comprometimento organizacional) e independente (práticas de administração de recursos humanos). É também entendida como uma pesquisa explicativa, pois visa esclarecer fatores que contribuem para a ocorrência de determinado fenômeno.

Em função do critério de acessibilidade e da restrição imposta pela empresa quanto à indicação das áreas para a coleta de dados, optou-se por realizar um estudo piloto centrado na filial de distribuição urbana localizada na cidade de Ribeirão Preto, São Paulo, que conta com um efetivo de 68 funcionários, e no escritório da Administração Central, sediado na região metropolitana de Belo Horizonte, Minas Gerais, que conta com um efetivo de 65 funcionários. Não obstante, tal restrição não ocasionou maiores dificuldades, uma vez que a amostra da pesquisa ( 68 funcionários de Ribeirão Preto e 25 da Administração Central) foi considerada representativa do universo pesquisado, conforme apresentado na Tabela I. A sua definição incluiu todos os grupos funcionais da empresa: funcionários operacionais, técnicos/administrativos, supervisores, coordenadores e gerentes. Esses grupos foram estratificados em:

a) nível operacional - escolaridade mínima: ensino fundamental;

b) técnico/administrativo - escolaridade mínima: ensino médio;

c) coordenação/gerência - escolaridade mínima: nível superior.

\section{TABELA I}

AMOSTRA ESTRATIFICADA

\begin{tabular}{lcc}
\hline \multicolumn{1}{c}{ CARGO } & FREQÜÊNCIA & \\
& ABSOLUTA & $\%$ \\
\hline Nível superior & 9 & 9,68 \\
Nível técnico/administrativo & 16 & 17,20 \\
Nível operacional & 68 & 73,12 \\
Total & 93 & 100,00 \\
\hline
\end{tabular}

Fonte: Dados da pesquisa.

A pesquisa foi conduzida em duas etapas. Na primeira, foram levantados dados sobre as práticas de RH. Para tal, foram utilizados: relatórios, documen- 
tos, manuais e normas de procedimentos existentes na XSA, além de registros, dados e percepções, obtidos por meio de observação, uma vez que um dos pesquisadores é funcionário da área de RH da XSA. A análise dos resultados desta etapa subsidiou a elaboração de questões específicas acerca das práticas de RH da empresa XSA, retratando as suas especificidades, como também complementou a análise dos resultados levantados por meio dos questionários.

Na segunda etapa, aplicou-se o questionário, com escala tipo Likert, adaptado a partir de Bandeira (I999), à amostra predefinida, contendo itens fechados e abertos. Efetuou-se o pré-teste, que possibilitou aferir o tempo de resposta, e efetivaram-se algumas correções, ocasionadas pela dificuldade de compreensão sobre as afirmações propostas.

O questionário foi estruturado em questões que abordam aspectos gerais do significado do trabalho, formação e trajetória ocupacional, situação do trabalho e aspectos ligados ao comprometimento e às práticas de $\mathrm{RH}$, incluindo as questões de gestão do conhecimento.

Para a análise dos dados dos questionários, utilizou-se o pacote estatístico SPSS (Statistic Package for Social Science), versão Io.o, para Windows. Buscouse avaliar a correlação existente entre a variável dependente (comprometimento) e a variável independente (práticas de recursos humanos), e quais dimensões do comprometimento se apresentam com maior ou menor significância. Para o tratamento e a análise dos dados, foi utilizada a estatística descritiva e analítica, com um processo de análise multivariado de tratamento dos dados, processados de acordo com cada objetivo da pesquisa, conforme apresentado no Quadro 2.

\section{QUADRO 2}

RESUMO DA ABORDAGEM METODOLOGICA

\begin{tabular}{lll}
\hline \multicolumn{1}{c}{ OBJETIVO GERAL } & \multicolumn{1}{c}{ QUESTÃO GERAL } & \multicolumn{1}{c}{ TRATAMENTO GERAL } \\
\hline $\begin{array}{l}\text { Discutir e analisar como as práti- } \\
\text { cas de recursos humanos impac- } \\
\text { tam o comprometimento organi- } \\
\text { zacional de seus funcionários. }\end{array}$ & $\begin{array}{l}\text { Quais são as práticas utilizadas pe- } \\
\text { la área Recursos Humanos na em- } \\
\text { presa XSA para conseguir o com- } \\
\text { prometimento dos funcionários? }\end{array}$ & $\begin{array}{l}\text { Tratamento multivariado dos dados, } \\
\text { usando técnicas estatísticas como: } \\
\text { média, porcentagens, análise fato- } \\
\text { rial e análise de regressão. }\end{array}$ \\
\hline \multicolumn{1}{c}{ OBJETIVOS ESPECÍFICOS } & QUESTÕES CONDUTORAS & TRATAMENTOS ESPECÍFICOS \\
\hline $\begin{array}{l}\text { Identificar as práticas de gestão } \\
\text { de recursos humanos da empresa. }\end{array}$ & $\begin{array}{l}\text { Quais são as práticas de gestão de } \\
\text { recursos humanos da XSA? }\end{array}$ & $\begin{array}{l}\text { Análise de entrevista profissional de } \\
\text { RH e observação. }\end{array}$ \\
\hline $\begin{array}{l}\text { Pesquisar e definir o tipo e o grau } \\
\text { de comprometimento existente } \\
\text { na organização. }\end{array}$ & $\begin{array}{l}\text { Qual é o tipo e o grau de com- } \\
\text { prometimento existente na orga- } \\
\text { nização? }\end{array}$ & Análise de cluster, estudo das médias. \\
\hline
\end{tabular}


QUADRO 2 (CONTINUAÇÃO)

\begin{tabular}{|c|c|c|}
\hline \multicolumn{3}{|c|}{ RESUMO DA ABORDAGEM METODOLOGICA } \\
\hline OBJETIVOS ESPECÍFICOS & QUESTÕES CONDUTORAS & TRATAMENTOS ESPECÍFICOS \\
\hline $\begin{array}{l}\text { Relacionar as práticas de recursos } \\
\text { humanos e o comprometimento } \\
\text { organizacional. }\end{array}$ & $\begin{array}{l}\text { Existe relação entre as práticas de } \\
\text { recursos humanos e o comprome- } \\
\text { timento? }\end{array}$ & Regressão linear múltipla. \\
\hline $\begin{array}{l}\text { Identificar os pontos críticos nas } \\
\text { práticas de recursos humanos; e } \\
\text { levantar recomendações e suges- } \\
\text { tões para melhoria do compro- } \\
\text { metimento. }\end{array}$ & $\begin{array}{l}\text { Existem pontos críticos nas práticas } \\
\text { de recursos humanos? }\end{array}$ & Análise dos dados anteriores. \\
\hline $\begin{array}{l}\text { Avaliar as escalas de comprometi- } \\
\text { mento organizacional e de práti- } \\
\text { cas de recursos humanos, incluin- } \\
\text { do a gestão do conhecimento. }\end{array}$ & $\begin{array}{l}\text { A escala de comprometimento é } \\
\text { confiável? A escala de práticas de } \\
\text { RH é confiável? }\end{array}$ & $\begin{array}{l}\text { Confiabilidade de uma nova escala: } \\
\text { Alfa de Cronbach. }\end{array}$ \\
\hline
\end{tabular}

Fonte: Silva (2003).

\subsection{CONFIABILIDADE DAS ESCALAS}

Para avaliar a confiabilidade das escalas de comprometimento e de práticas de RH, optou-se pelo método de consistência interna, utilizando-se o Alfa de Cronbach. Segundo Malhotra (200I), um valor de Alfa de Cronbach superior a o,6 indica confiabilidade satisfatória da consistência interna. Os valores do Alfa de Cronbach para cada uma das dimensões do comprometimento afetivo, instrumental e normativo são apresentados na Tabela 2. Conclui-se que a escala de comprometimento pode ser considerada confiável, pois foram encontrados valores de Alfa aceitáveis para os três fatores do comprometimento afetivo $(0,7885)$, normativo $(0,6079)$ e instrumental $(0,5789)$. Embora o comprometimento instrumental tenha apresentado um valor próximo a o,6, acredita-se que o mesmo também possa ser considerado como aceitável.

\section{TABELA 2}

VALOR DE ALFA PARA AS ESCALAS DE COMPROMETIMENTO

\begin{tabular}{ccccc}
\hline NOME & OUESTÃO & $\begin{array}{c}\text { CORRELACÃO } \\
\text { ITEM-TOTAL }\end{array}$ & $\begin{array}{c}\text { ALFA (SE O ITEM } \\
\text { FOR RETIRADO) }\end{array}$ & ALFA TOTAL \\
\hline \multirow{3}{*}{ Afetivo } & 1 & 0,4119 & 0,8006 & \\
& 9 & 0,6359 & 0,7248 & 0,7885 \\
& 17 & 0,5055 & 0,7690 & \\
\hline
\end{tabular}




\section{TABELA 2 (CONTINUAÇÃO)}

VALOR DE ALFA PARA AS ESCALAS DE COMPROMETIMENTO

\begin{tabular}{ccccc}
\hline NOME & QUESTÃO & $\begin{array}{c}\text { CORRELACÃO } \\
\text { ITEM-TOTAL }\end{array}$ & $\begin{array}{c}\text { ALFA (SE O ITEM } \\
\text { FOR RETIRADO) }\end{array}$ & ALFA TOTAL \\
\hline \multirow{6}{*}{ Normativo } & 3 & 0,2846 & 0,6183 & \\
& 19 & 0,4199 & 0,5122 & \\
& 29 & 0,2948 & 0,7861 & 0,6079 \\
& 33 & 0,4468 & 0,4913 & \\
\multirow{5}{*}{ Instrumental } & 38 & 0,4191 & 0,5220 & \\
& 2 & 0,2977 & 0,5439 & 0,5789 \\
& 10 & 0,3996 & 0,4862 & \\
& 18 & 0,4450 & 0,4610 & \\
\hline
\end{tabular}

Fonte: Dados da pesquisa.

Os mesmos procedimentos estatísticos foram utilizados para a escala de recursos humanos. A Tabela 3 apresenta os resultados das correlações internas das variáveis de RH, bem como o Alfa de Cronbach obtido em cada questão avaliada.

De acordo com os resultados, ao eliminar as questões 5, II e 20 do fator I (gestão do conhecimento), verificou-se que o Alfa de Cronbach aumentou a consistência da subescala. O mesmo pôde ser constatado no fator 2 ao se retirar a questão 37. Já os fatores 6, 7 e 8 (segurança no trabalho, comunicação, recrutamento e seleção, respectivamente) não apresentaram valores de Alfa aceitáveis, indicando que não existe consistência interna entre esses itens. Optou-se, portanto, por desconsiderá-los na análise. Dessa forma, a escala de recursos humanos foi reduzida para cinco fatores, cujos valores de Alfa são considerados aceitáveis para se afirmar que ela é fidedigna. Após a retirada dos itens mencionados, foi rodada novamente a análise fatorial para cada um dos cinco fatores isoladamente. Concluiu-se, portanto, que também a escala de recursos humanos pode ser confirmada, pois das oito variáveis investigadas e avaliadas inicialmente cinco revelaram boa consistência interna, apresentando um Alfa de Cronbach significativo. A gestão do conhecimento apresentou o maior índice $(0,7856)$, seguido de treinamento e desenvolvimento (com Alfa 0,7465), vindo logo após a carreira (com 0,7097), acompanhado de remuneração (com o,6947), e, finalmente, o relacionamento (com um Alfa de 0,6040$)$. 
TABELA 3

VALOR DE ALFA PARA AS PRATTICAS DE RECURSOS HUMANOS

\begin{tabular}{|c|c|c|c|c|c|}
\hline FATOR & NOME & QUESTÃO & $\begin{array}{l}\text { CORRELACÃO } \\
\text { ITEM-TOTAL }\end{array}$ & $\begin{array}{l}\text { ALFA (SE O ITEM } \\
\text { FOR RETIRADO) }\end{array}$ & ALFA TOTAL \\
\hline \multirow[t]{10}{*}{1} & \multirow{10}{*}{$\begin{array}{l}\text { Gestão } \\
\text { do conhecimento }\end{array}$} & 4 & 0,4815 & 0,7654 & \multirow{10}{*}{0,7856} \\
\hline & & 5 & 0,3013 & 0,7861 & \\
\hline & & 11 & 0,2948 & 0,7877 & \\
\hline & & 12 & 0,6141 & 0,7466 & \\
\hline & & 13 & 0,5884 & 0,7488 & \\
\hline & & 20 & 0,3217 & 0,7852 & \\
\hline & & 21 & 0,5382 & 0,7578 & \\
\hline & & 28 & 0,6395 & 0,7474 & \\
\hline & & 35 & 0,3738 & 0,7768 & \\
\hline & & 36 & 0,4846 & 0,7654 & \\
\hline \multirow[t]{3}{*}{2} & \multirow[t]{3}{*}{ Relacionamento } & 22 & 0,4915 & 0,3889 & \multirow{3}{*}{0,6040} \\
\hline & & 30 & 0,4587 & 0,4436 & \\
\hline & & 37 & 0,3065 & 0,6724 & \\
\hline \multirow[t]{2}{*}{3} & \multirow[t]{2}{*}{ Remuneração } & 7 & 0,5334 & - & \multirow[t]{2}{*}{0,6947} \\
\hline & & 15 & 0,5334 & - & \\
\hline \multirow[t]{2}{*}{4} & \multirow{2}{*}{$\begin{array}{l}\text { Treinamento } \\
\text { e desenvolvimento }\end{array}$} & 8 & 0,5958 & - & \multirow[t]{2}{*}{0,7465} \\
\hline & & 39 & 0,5958 & - & \\
\hline \multirow[t]{2}{*}{5} & \multirow[t]{2}{*}{ Carreira } & 16 & 0,5501 & - & \multirow[t]{2}{*}{0,7097} \\
\hline & & 24 & 0,5501 & - & \\
\hline \multirow[t]{2}{*}{6} & Segurança & 23 & $-0,0081$ & - & \multirow[t]{2}{*}{$-0,0156$} \\
\hline & no trabalho & 31 & $-0,0081$ & - & \\
\hline \multirow[t]{2}{*}{7} & Comunicação & 27 & 0,0851 & - & \multirow[t]{2}{*}{0,1540} \\
\hline & & 34 & 0,0851 & - & \\
\hline \multirow[t]{2}{*}{8} & Recrutamento & 6 & 0,3338 & - & \multirow[t]{2}{*}{0,5005} \\
\hline & e seleção & 14 & 0,3338 & - & \\
\hline
\end{tabular}

Fonte: Dados da pesquisa.

\subsection{A EMPRESA XSA}

A empresa pesquisada, de modo a preservar o sigilo, foi denominada de XSA. Fundada em I967, em Minas Gerais, atua no ramo de logística em âmbito nacional, possuindo 35 filiais. A gestão da corporação é integrada e sistematizada, sendo que todas as áreas atuam focadas em cinco campos de resultado estabelecidos pelo Conselho Administrativo: a) gestão de pessoas; b) imagem e comunicação; c) processos (saúde, segurança e meio ambiente, qualidade); d) tecnologia da informação; e) econômico-financeiro. A XSA apresentou, nos últimos quatro anos, um crescimento em seu faturamento na ordem de $60 \%$, sendo classificada como o 7ํㅡㄹ maior operador logístico da América Latina no ano de 2002. Em 200I, foi 
classificada entre as ioo melhores empresas para se trabalhar no país, devido às práticas adotadas pela gestão de recursos humanos (Guia Exame, 200I). Possui 2.298 funcionários, distribuídos nos três segmentos, estruturados em unidades de negócios distintas. A área administrativa conta com 46 funcionários locados no escritório central, responsáveis pela formulação das diretrizes e políticas corporativas de RH e pela operacionalização da função na região.

A área de RH da XSA é representada por uma Gerência de Desenvolvimento Organizacional, responsável por todos os subsistemas de recursos humanos. Está ligada diretamente ao diretor superintendente da empresa e conta com I2 funcionários. Nas demais unidades e filiais, o gerente é responsável pela administração de seus recursos humanos. A gestão de pessoas na XSA é considerada como uma das funções gerenciais, sendo, portanto, uma operação descentralizada.

O sistema de recrutamento e seleção segue a tendência atual de mercado de descentralizar e terceirizar a captação de profissionais, bem como as avaliações psicológicas para testes de seleção e de avaliação de potencial. Busca-se aproveitar os próprios colaboradores para as novas oportunidades, por meio das promoções internas, com a indicação da chefia imediata, que se pauta nos resultados individuais e nas habilidades dos colaboradores. A área de Treinamento e Desenvolvimento tende a atuar de forma estratégica, privilegiando a formação de competências pessoais e profissionais de todos os seus níveis operacionais, técnicos, administrativos e gerenciais. Há um programa de integração dos novos funcionários, realizado pelo gerente, coordenador e/ou supervisor da filial contratante. A política de remuneração segue os valores oferecidos pelo mercado. Contudo, não existe ainda uma política ou um sistema de remuneração e de carreira formalizados e divulgados na organização. A segurança no trabalho busca subsidiar os gerentes e coordenadores em termos dos principais aspectos de segurança, formando uma cultura de liderança educadora, para poder atuar na prevenção e minimização dos riscos do ambiente.

As práticas de gestão do conhecimento, recentemente implantadas de forma mais sistemática na empresa, apontam para o compartilhamento de objetivos organizacionais, bem como para um ambiente que facilita a troca de idéias e a comunicação entre as pessoas, possibilitando um ambiente de maior integração dos colaboradores. Por meio de programas institucionais, a empresa incentiva a formação educacional continuada, desde a suplência do ensino fundamental e do ensino médio até a graduação e a pós-graduação (lato e stricto sensu). Para a democratização da informação, são utilizadas ferramentas de comunicação (quadro de avisos, e-mail, intranet, jornais e boletins internos), descrição de procedimentos operacionais e administrativos, além da difusão das melhores práticas, conforme aponta Cisalpino (2002).

Comparando-se as práticas de recursos humanos da empresa XSA com o quadro evolutivo da função recursos humanos no Brasil, verifica-se que a gestão de 
RH da empresa tende à atuação sistêmica, apresentando funções desenvolvidas e buscando um posicionamento estratégico quanto às diretrizes organizacionais, que visa, por meio de seus programas e projetos, promover continuamente o desenvolvimento pessoal e profissional de seus colaboradores. $\mathrm{O}$ foco no relacionamento interpessoal é uma prática constante em todos os níveis da organização, o que propicia um ambiente de trabalho amigável e de companheirismo nas relações de trabalho. Tais informações evidenciam, portanto, a existência de práticas estruturadas de RH, bem como de gestão do conhecimento.

\section{3 - 3 ANÁLISE E DISCUSSÃO DOS DADOS}

Os resultados apurados nos 93 questionários aplicados demonstram que $o$ perfil da amostra pode ser assim configurado: $90 \%$ são do sexo masculino; $52 \%$ são casados; $42 \%$ situam-se na faixa etária entre 25 e 30 anos; $67 \%$ concluíram o ensino médio; 87,5\% trabalham na empresa há menos de cinco anos; 6I,4\% atuam na área operacional; 80,7\% recebem menos de R \$ I.200,00 por mês. Essa caracterização da amostra reflete a realidade da empresa, conforme dados levantados na área de RH, podendo-se concluir que é representativa da população da XSA.

Garantida a validade da escala, apurou-se, por meio da média de cada variável, um escore para cada uma das três dimensões da escala de comprometimento e para as cinco escalas de recursos humanos. A Tabela 4 apresenta os escores dos oito fatores observados na amostra. Pode-se observar que gestão do conhecimento apresenta a maior de todas as médias das práticas de RH $(5,63)$, seguida de relacionamento $(5,59)$. A menor média foi remuneração, com média de 3,82. Quanto aos padrões de comprometimento observados na amostra, observou-se: o afetivo, média de 5,29; o normativo, 4,72; e o instrumental, 4,26.

TABELA 4

DESCRICZAO DAS VARIÂVEIS

\begin{tabular}{lcccc}
\hline \multicolumn{1}{c}{ VARIÁVEL } & INTERVALO DE CONFIANÇA PARA A MÉDIA (95\%) & \\
\hline CAFET & LIMITE INFERIOR & MÉDIA & LIMITE SUPERIOR & DESVIO PADRÃO \\
CNORM & 5,01 & 5,29 & 5,58 & 1,35 \\
CINST & 4,40 & 4,72 & 5,04 & 1,52 \\
Gestão do conhecimento & 3,95 & 4,26 & 4,57 & 1,48 \\
Remuneração & 5,37 & 5,63 & 5,90 & 1,25 \\
Treinamento e desenvolvimento & 3,42 & 3,82 & 4,22 & 1,89 \\
Relacionamento & 5,14 & 5,48 & 5,83 & 1,63 \\
Carreira & 5,27 & 5,59 & 5,92 & 1,55 \\
& 4,21 & 4,62 & 5,02 & 1,91 \\
\hline
\end{tabular}

Fonte: Dados da pesquisa.

Obs.: CAFET $=$ comprometimento afetivo; CNORM = comprometimento normativo; CINST $=$ comprometimento instrumental. 
Pode-se levantar a hipótese de que as maiores médias observadas para gestão do conhecimento e para relacionamento, associadas à maior média do comprometimento afetivo, possam ser explicadas pelo tipo de empresa, de origem familiar, favorecendo um ambiente de trabalho amigável e de companheirismo nas relações de trabalho. Essa empresa, em constante busca de profissionalização de todas as suas áreas, vem investindo fortemente no desenvolvimento pessoal e no profissional, por intermédio de programas de formação ou de incentivo à educação continuada de todos os seus colaboradores, o que favorece o estabelecimento e a manutenção dos vínculos afetivos com a empresa e fortalece o sentimento de permanecer ligado a ela.

Com o objetivo de agrupar os indivíduos em padrões de comprometimento específicos, optou-se por utilizar a metodologia utilizada por Medeiros (I997), que agrupa e combina as diversas categorias, conforme apresentado na Tabela 5.

\section{TABELA 5}

CLAS SIFICAÇAO DO COMPROMETIMENTO EM CLUSTERS

\begin{tabular}{lcc}
\hline \multicolumn{1}{c}{ GRUPO } & FREQ. ABS. & FREQ. \% \\
\hline Comprometido nas três dimensões & 46 & 52,3 \\
Descomprometido nas três dimensões & 1 & 1,1 \\
Comprometido apenas normativamente & 2 & 2,3 \\
Comprometido apenas afetivamente & 10 & 11,4 \\
Comprometido apenas instrumentalmente & 4 & 4,5 \\
Comprometido normativa-afetivamente & 17 & 19,3 \\
Comprometido normativa-instrumentalmente & 2 & 2,3 \\
Comprometido afetiva-instrumentalmente & 6 & 6,8 \\
\hline Total & 88 & 100 \\
\hline
\end{tabular}

Fonte: Dados da pesquisa.

Pode-se constatar que $98,9 \%$ da amostra estudada são comprometidos, sendo que apenas um caso não se encontra comprometido em nenhuma das três dimensões. Observa-se que 52,3\% dos funcionários pesquisados estão comprometidos nas três dimensões. Os escores de maior relevância foram os comprometidos normativa-afetivamente (19,3\%), seguidos de comprometidos afetivamente, com um escore de II,4\%. Esse resultado talvez possa ser atribuído ao incentivo ao desenvolvimento pessoal e profissional, que é uma diretriz da alta direção, e ao clima e ambiente de companheirismo, conforme mencionado anteriormente. 
O relacionamento entre as escalas de comprometimento organizacional demonstrou que a maioria das práticas de $\mathrm{RH}$ (cinco das oito avaliadas) influencia nas dimensões dos comprometimentos afetivo e normativo, o que possibilita afirmar que existe uma relação linear positiva entre as variáveis analisadas. Os resultados dos modelos são apresentados nas Tabelas 6 e 7 .

\section{TABELA 6}

REGRESSAOO ENTRE AS PRATICAS DE RECURSOS HUMANOS (VARIÁVEL INDEPENDENTE) E O COMPROMETIMENTO NORMATIVO (DEPENDENTE)

\begin{tabular}{lcccc}
\hline \multicolumn{1}{c}{ VARIÁVEL } & \multicolumn{2}{c}{ COEFICIENTES } & & \\
& NÃO PADRONIZADOS & PADRONIZADOS & VALOR P & TOLERÂNCIA \\
\hline Constante & 1,693 & - & 0,013 & - \\
Gestão do conhecimento & $-0,080$ & $-0,067$ & $\mathbf{0 , 5 9 4}$ & 0,439 \\
Remuneração & 0,020 & 0,026 & $\mathbf{0 , 8 0 8}$ & 0,600 \\
T D\&E & 0,000 & 0,002 & $\mathbf{0 , 9 8 0}$ & 0,763 \\
Relacionamento & 0,273 & 0,279 & 0,014 & 0,560 \\
Carreira & 0,404 & 0,509 & 0,000 & 0,420 \\
\hline
\end{tabular}

Fonte: Dados da pesquisa.

Obs.: Os valores p em negrito indicam variáveis não significativas para a explicação do comprometimento normativo.

Pode-se verificar que as práticas ligadas ao relacionamento e à carreira explicam o comprometimento normativo. O poder de explicação do modelo (R2) é de $43,6 \%$ da variabilidade do comprometimento normativo. No comprometimento normativo, os indivíduos apresentam certos comportamentos porque acreditam que é o mais correto a se fazer, e não porque eles pressupõem que obterão benefícios pessoais. A partir da análise das questões, pode-se supor que os funcionários já tenham introjetado como norma e valor da empresa que as promoções se baseiam em competência e relacionamento interpessoal. Nesta empresa, não existe um plano de carreira formalizado e sistematizado. As promoções dos colaboradores são efetivadas a partir da avaliação e da indicação da chefia imediata, que detém a responsabilidade e a função de acompanhar o desenvolvimento profissional e pessoal de seus colaboradores. Nessas indicações, em regra, a chefia avalia as competências técnicas, os resultados operacionais e as habilidades interpessoais, estas associadas à manutenção do bom ambiente de trabalho. 
TABELA 7

REGRESSAO ENTRE AS PRATICAS DE RECURSOS HUMANOS

(VARIÁVEL INDEPENDENTE) E O COMPROMETIMENTO AFETIVO (DEPENDENTE)

\begin{tabular}{lcccc}
\hline \multicolumn{1}{c}{ VARIÁVEL } & \multicolumn{2}{c}{ COEFICIENTES } & & \\
& NÃO PADRONIZADOS & PADRONIZADOS & VALOR P & TOLERÂNCIA \\
\hline Constante & 1,204 & - & 0,035 & - \\
Gestão do conhecimento & 0,353 & 0,326 & 0,007 & 0,439 \\
Remuneração & 0,167 & 0,234 & 0,024 & 0,600 \\
T D\&E & 0,098 & 0,118 & $\mathbf{0 , 1 9 4}$ & 0,763 \\
Relacionamento & 0,107 & 0,122 & $\mathbf{0 , 2 4 8}$ & 0,560 \\
Carreira & 0,070 & 0,102 & $\mathbf{0 , 4 0 3}$ & 0,420 \\
\hline
\end{tabular}

Fonte: Dados da pesquisa.

Obs.: Os valores p em negrito indicam variáveis não significativas para a explicação do comprometimento afetivo.

Pode-se verificar que as práticas de gestão do conhecimento e de remuneração explicam o comprometimento afetivo. O poder de explicação do modelo (R2) é de $49,2 \%$ da variabilidade do comprometimento afetivo. As práticas de geração e difusão do conhecimento, assim como o sistema de remuneração, influenciam mais significativamente e fortalecem os vínculos afetivos com a organização, demonstrando, fundamentalmente, uma preocupação constante da empresa em incentivar, valorizar e promover o constante aperfeiçoamento pessoal e profissional dos empregados.

Verifica-se que os funcionários identificam-se com as normas e os valores da organização, percebendo-se participação e esforço para contribuir significativamente com a empresa. Este é o vínculo forte estabelecido com a empresa, pois ele é alimentado pelos sentimentos do indivíduo, que acata os valores organizacionais, identificando e assimilando-os como se fossem seus. Esta relação ativa entre o indivíduo e a organização fortalece no indivíduo o desejo de permanecer como membro da empresa.

Em relação ao comprometimento instrumental, o valor do coeficiente de determinação do modelo é muito baixo, indicando que ele não pode ser explicado pelas práticas de recursos humanos da empresa. O comprometimento instrumental baseia-se nas trocas que o indivíduo faz com a organização, tais como salário, tempo investido e benefícios. É interessante ressaltar que também na pesquisa de Bandeira (I999) o comprometimento instrumental apresentou fraca correlação com as variáveis estudadas, destacando-se também a pouca importância das práticas de recursos humanos na manutenção deste tipo de comprometimento. 


\section{CONSIDERAÇÕES FINAIS}

Descobrir o que é ser comprometido com o trabalho e com a vida e obter o conhecimento da medida em que as práticas de RH contribuem para o comprometimento do indivíduo na organização foram os fatores que impulsionaram e estimularam esta pesquisa. Os seus resultados permitiram concluir que existe uma relação envolvendo as práticas de recursos humanos e as práticas de gestão do conhecimento como o tipo e o grau de comprometimento dos funcionários da empresa XSA. Estabelecer essa relação, principalmente com a gestão do conhecimento, significa um avanço em termos do conhecimento acadêmico, podendo também propiciar ferramenta para uma atuação no nível empresarial, na medida em que o comprometimento é um instrumento de interesse recíproco: indivíduo/organização.

A partir dos dados apresentados sobre a administração de recursos humanos na empresa XSA, pode-se concluir que as práticas de recursos humanos enquadram-se na perspectiva sistêmica, tendendo à gestão estratégica. As políticas das diversas funções, como recrutamento e seleção, treinamento e desenvolvimento, carreira, remuneração, relacionamento, comunicação e segurança no trabalho, são estabelecidas em nível corporativo por um staff de especialistas em RH e desempenhadas operacionalmente pelos gerentes e coordenadores das unidades de negócio e das filiais. Algumas unidades contam com uma equipe de especialistas em RH: analista, assistente e técnico em segurança do trabalho.

Quanto aos padrões de comprometimento, observou-se que o comprometimento afetivo apresentou os escores mais altos, seguidos do normativo e do instrumental. A partir da análise de clusters, constatou-se que quase a totalidade da amostra estudada é comprometida, sendo que 52,3\% estão comprometidos nas três dimensões, apurando-se apenas um caso de não comprometimento em nenhuma das três dimensões. Na amostra, predominam os comprometidos normativa-afetivamente, seguidos de comprometidos afetivamente.

Verificou-se que gestão do conhecimento, remuneração, relacionamento, treinamento, desenvolvimento e educação, e carreira influenciam as dimensões afetiva e normativa do comprometimento, embora demonstrem fracas correlações com o comprometimento instrumental. Os índices mais elevados foram observados nas atividades ligadas à gestão do conhecimento e ao relacionamento, denotando que estas práticas constituem fortes fatores para a manutenção do vínculo dos funcionários com a empresa pesquisada.

O sistema de remuneração existente na empresa assegura uma prática de pagamento de salários segundo os padrões estabelecidos pelo mercado. Entretanto, não há ainda um plano de carreira e um sistema de remuneração formal estabelecido. Isso pode ser confirmado pela baixa média atribuída às práticas de 
remuneração. Assim, é importante que sejam criadas diretrizes básicas e que sejam desenvolvidos programas formais de carreira e de remuneração. Essa preocupação já é demonstrada pela empresa, que recentemente decidiu pela implantação de uma coordenação de remuneração.

Embora não tenha sido possível correlacionar os fatores de recrutamento e seleção, comunicação e segurança do trabalho, referentes às práticas de recursos humanos voltadas para o comprometimento, isto não significa que tais práticas não existam e que não sejam desenvolvidas na empresa pesquisada. Futuros estudos e pesquisas nesta área poderão investigar a correlação destas práticas de RH com as dimensões do comprometimento, elaborando outras questões que possam aferir tais práticas.

Os dados da pesquisa realizada indicam a importância das práticas de gestão do conhecimento e de remuneração para o estabelecimento do comprometimento dos funcionários com a empresa. Conforme já comentado, apesar de não estar completamente implementada a gestão do conhecimento na empresa, suas práticas já são percebidas pelos funcionários. Assim, é importante que haja um investimento maior nessas práticas, estabelecendo e formalizando a gestão do conhecimento.

A questão da remuneração é reforçada pela baixa média do fator e pelas respostas ao questionário. Se acaso os entrevistados tivessem a possibilidade de optar por uma outra organização para se trabalhar, escolheriam uma empresa que praticasse melhores políticas de remuneração. Os dados de entrevista e a observação apontam a ausência de um sistema de remuneração formalmente estabelecido, embora a grande maioria dos salários praticados pela empresa esteja na média do mercado.

Observa-se também que a inexistência de um modelo de planejamento e desenvolvimento de carreira ocupou dois dos cinco itens mais eleitos pelos funcionários caso pudessem escolher uma outra empresa para se trabalhar. Portanto, o estabelecimento de um planejamento de carreira e de um sistema de remuneração pode contribuir para fortalecer os laços de comprometimento dos funcionários com a empresa.

Por fim, o instrumento utilizado nesta pesquisa pode ser considerado com grau de confiabilidade adequado, tanto para a escala do comprometimento como para as práticas de recursos humanos adotadas na empresa XSA. O teste de unidimensionalidade indicou que os itens que compõem as subescalas produzem apenas um fator - verificado em cada uma das subescalas.

É importante destacar que toda investigação empírica apresenta limitações muito variadas, não podendo o pesquisador tomar como verdade absoluta as conclusões e os comentários destacados neste trabalho. Deve-se considerar a limitação da amostra utilizada para este estudo piloto, que, apesar de representativa 
da população da empresa em termos de características demográficas, restringese a duas áreas específicas. Entretanto, pode-se concluir que os resultados propostos foram atingidos. Resumindo, a principal conclusão desta pesquisa foi que as práticas de recursos humanos adotadas pela empresa XSA contribuem para a manutenção dos vínculos do comprometimento organizacional em duas das dimensões investigadas: a afetiva e a normativa. Dessa forma, pode-se afirmar que a organização apresenta instrumentos que orientam as suas práticas de RH para a manutenção e consolidação destes comprometimentos.

Para a empresa pesquisada, esta investigação permitiu identificar os pontos fortes de suas práticas de recursos humanos: gestão do conhecimento, relacionamento, treinamento e desenvolvimento, que fortalecem o vínculo dos empregados com a organização. Foi detectada a necessidade de fortalecer outras práticas, aqui identificadas como carreira e remuneração, a fim de se consolidar estes vínculos.

O modelo proposto por esta pesquisa buscou acrescentar a gestão do conhecimento, que é uma prática organizacional emergente em várias empresas brasileiras. Assim, no instrumento de levantamento de dados foram incorporadas e validadas questões que visaram aferir a prática de gestão do conhecimento. Essa nova escala poderá ser utilizada em futuras investigações acadêmicas, com o intuito de correlacionar esta prática com o comprometimento organizacional, como fator que poderá ser alavancador para a criação e manutenção do vínculo dos funcionários com a organização.

Sugere-se para a academia que outras pesquisas na área abordem as práticas tradicionais de recursos humanos, incluindo a prática de gestão do conhecimento, levantada por esta pesquisa, e as suas correlações com o comprometimento organizacional. Este campo é extenso para novas pesquisas, pois, além da complexidade do tema, permite associar novas práticas de gestão de recursos humanos e também investigar o conteúdo das relações que permeiam as trocas entre indivíduo e organização.

\section{REFERÊNCIAS}

ALBUQUERQUE, L. G.; MARQUES, G. M.; MEDEIROS, C. A. F.; SIQUEIRA, M. Um estudo exploratório dos múltiplos componentes do comprometimento organizacional. Read, v. II, n. I, p. 43, jan.fev. 2005.

BANDEIRA, M. L. Investigando o impacto das políticas de recursos humanos no comprometimento organizacional em uma empresa de serviços do setor público. I999. Dissertação (Mestrado em Administração) - Faculdade de Ciências Econômicas, Universidade Federal de Minas Gerais, Belo Horizonte, I999. 
BASTOS, A. V. B. Comprometimento no trabalho: a estrutura dos vínculos do trabalhador com a organização, a carreira e o sindicato. I994. Tese (Doutorado em Psicologia) - Instituto de Psicologia, Universidade de Brasília, Brasília, I994.

BORGES-ANDRADE, J. E. Comprometimento organizacional na administração pública e em seus segmentos meio e fim. In: REUNIÃO ANUAL DE PSICOLOGIA, XIX, I989, Ribeirão Preto. Anais... Ribeirão Preto: Sociedade de Psicologia, I989.

CAMPOS, R. L.; BARBOSA, F. V. Gestão do conhecimento: o conhecimento como fonte de vantagem competitiva sustentável. In: ENANPAD, 25., 200I. Campinas. Anais eletrônicos. Campinas: ANPAD, 200I.

CISALPINO, L. S. Gestão do conhecimento e learning organization - propostas para a competitividade: estudo de caso em empresa do setor de serviços. 2002. Dissertação (Mestrado em Administração) - Fundação Pedro Leopoldo, Pedro Leopoldo, 2002.

DAVENPORT, T.; PRUSAK, L. Conhecimento empresarial: como as organizações gerenciam o seu capital intelectual. Rio de Janeiro: Campus, I998.

DIAS, D. S.; MARQUES, A. L. Múltiplos comprometimentos: um estudo com profissionais e gerentes de uma grande empresa do setor metal-mecânico. In: ENANPAD, 26., 2002. Salvador. Anais eletrônicos. Salvador: ANPAD, 2002.

DIAS, D. V. Valores organizacionais, modelos e práticas de gestão de pessoas e comprometimento organizacional: um estudo em empresas selecionadas do setor siderúrgico mineiro. 2005. Tese (Doutorado em Administração) - Faculdade de Ciências Econômicas, Universidade Federal de Minas Gerais, Belo Horizonte, 2005.

EDVINSSON, L.; MALONE, M. S. Capital intelectual. São Paulo: Makron Books, I998. FERREIRA, A. B. Estabelecendo vínculos no trabalho: um estudo sobre a situação de trabalho e o comprometimento de gerentes em uma empresa de telefonia. 200I. Dissertação (Mestrado em Administração) - Faculdade de Ciências Econômicas, Universidade Federal de Minas Gerais, Belo Horizonte, 200I.

FLEURY, A.; FLEURY, M. T. L. Estratégias empresariais e formação de competências: um quebra-cabeça caleidoscópio da indústria brasileira. São Paulo: Atlas, 2000.

FLEURY, M. T. L. FISCHER, R. M. Relações de trabalho e políticas de gestão: uma história das questões atuais. In: ENANPAD, ı6., ı992. Canela Anais... Canela: ANPAD, I992.

FILENGA, D.; REBECHI, R. Percepções de justiça e comprometimento organizacional em uma ONG. In: ENANPAD, 29., 2005, Brasília. Anais eletrônicos. Brasília: ANPAD, 2005 .

FONSECA, C. A. M.; BASTOS, A. V. B. Criatividade e comprometimento organizacional: suas relações com a percepção de desempenho no trabalho. In: ENANPAD, 26., 2002. Salvador. Anais eletrônicos. Salvador: ANPAD, 2002.

GAMA, P. R. V. Comprometimento organizacional em instituição pública de pesquisa. I993. Dissertação (Mestrado em Administração) - Faculdade de Ciências Econômicas, Universidade Federal de Minas Gerais, Belo Horizonte, I993.

GENELHU, P. S. Retenção de talentos via comprometimento: um estudo na PUC Minas Arcos. 2004. Dissertação (Mestrado Profissional em Administração) - Fundação Pedro Leopoldo, Pedro Leopoldo, 2004 .

GUIA EXAME 200ı: I00 melhores empresas para você trabalhar. São Paulo: Abril, ano 35, n. I8, set. 200 I. 
LEONARD-BARTON, D. Nascentes do saber: criando e sustentando as fontes de inovação. Rio de Janeiro: FGV, I998. p. I63-206.

LINS, C. R. G.; ZÚNIGA, M. Administração de recursos humanos - teoria geral e prática em empresas mineiras. In: ENANPAD, 23., Foz do Iguaçu, set. I999. Anais eletrônicos. Rio de Janeiro: ANPAD.

MALHOTRA, N. K. Pesquisa de marketing. uma orientação aplicada. 3. ed. Porto Alegre: Bookman, 200I.

McGEE, G. W.; FORD, R. C. Two (or more?) dimensions of organizational commitment: reexamination of the affective and continuance commitment scales. Journal of Applied Psychology, 72 (4), p. 638-64I, I987.

MEDEIROS, C. A. F. Comprometimento organizacional, características pessoais e performance no trabalho: um estudo dos padrões de comprometimento organizacional. I997. Dissertação (Mestrado em Administração) - Centro de Ciências Sociais Aplicadas, Universidade Federal do Rio Grande do Norte, Natal, I997.

MEYER, J. P.; ALLEN, N. J. A three-component conceptuatization of organizational commitment. Human Resource Management Review, v. I, p. 6I-89, I991.

- Testing "side-bet theory" of organizational commitment: some methodological considerations. Journal of Applied Psychology, 69 (3), p. 372-378, I984.

MEYER, J. P.; ALLEN, N. J.; GELLATLY, I. R. Affective and continuance commitment to the organization: evaluation of measures and analysis of concurrent and time-lagged relations. Journal of Applied Psychology, 75 (6), p. 710-720, I990.

MORAES, L. F. R. Comprometimento organizacional das universidades federais mineiras: um exercício preliminar de análise. Belo Horizonte: Faculdade de Ciências Econômicas da UFMG, I997. (Relatório de pesquisa).

; MARQUES, A. L. Comprometimento organizacional: um estudo de caso comparativo nas universidades federais mineiras. Belo Horizonte: UFMG/FACE/CEPEAD, I996 (Relatório de pesquisa).

MOWDAY, R. T.; PORTER, L. W.; STEERS, R. M. Employee organization linkage: the psychology of commitment, absenteism and turnover. New York: Academic Press, I982.

- The measurement of organizational commitment. Journal of Vocational Psycho$\log$, I4, p. 224-247, I979.

RANGEL, H. R. Comprometimento organizacional na administração pública municipal: um estudo na Prefeitura de Vitória. 200I. Dissertação (Mestrado em Administração) - Faculdade de Ciências Econômicas, Universidade Federal de Minas Gerais, Belo Horizonte, 200I. REGO, A.; SOUTO, S. A percepção da justiça como antecedente do comprometimento organizacional: um estudo luso-brasileiro. Revista de Administração Contemporânea, v. 8, n. I, p. I5I-I57, 2004.

SARSUR, A. M. Empregabilidade $x$ empresabilidade. In: ENANPAD, 2I., I997, Rio das Ostras. Anais... Rio de Janeiro: ANPAD, I997. p. I-I5.

SILVA, E. M. da. Práticas de recursos humanos e seus impactos no comprometimento organizacional em uma empresa de logística. 2003. Dissertação (Mestrado Profissional em Administração) - Fundação Pedro Leopoldo, Pedro Leopoldo, 2003.

TAMAYO, A. Relação entre os valores do empregado e o comprometimento organizacional afetivo. In: ENANPAD, 24., 2000. Florianópolis. Anais eletrônicos. Florianópolis: ANPAD, 2000. 
TERRA, José Cláudio C. Gestão do conhecimento; o grande desafio empresarial: uma abordagem baseada no aprendizado e na criatividade. São Paulo: Negócio, 2000. Cap. 5.

ULRICH, D. Os campeões de recursos humanos. Inovando para obter os melhores resultados. São Paulo: Futura, I998.

VASCONCELOS, M. C. R. L. O processo de aprendizagem e a gestão do conhecimento em empresas mineiras de vanguarda. In: ENANPAD, 26., 2002. Salvador. Anais eletrônicos. Salvador: ANPAD, 2002.

WOOD, JR., T. Mudança organizacional e transformação da função de recursos humanos. In: WOOD, JR., T. (Coord.). Mudança organizacional: aprofundando temas atuais em administração de empresas. São Paulo: Atlas, I995· p. 22I-242.

ZEHURI, E. Comprometimento organizacional: um estudo de caso na Justiça do Trabalho da Terceira Região. I997. Dissertação (Mestrado em Administração) - Faculdade de Ciências Econômicas, Universidade Federal de Minas Gerais, Belo Horizonte, I997.

\section{TRAMITAÇÃO}

Recebido em 30/09/2004

Aprovado em 15/06/2006 
Copyright of Revista de Administração Mackenzie is the property of Universidade Presbiteriana Mackenzie, RAM-Revista de Administracao Mackenzie and its content may not be copied or emailed to multiple sites or posted to a listserv without the copyright holder's express written permission. However, users may print, download, or email articles for individual use. 